\title{
Williams syndrome and its cognitive profile: the importance of eye movements
}

This article was published in the following Dove Press journal:

Psychology Research and Behavior Management

3 June 2015

Number of times this article has been viewed

\section{Jo Van Herwegen}

Department of Psychology, Kingston University London, Surrey, UK
Correspondence: Jo Van Herwegen Department of Psychology, Kingston University London, Penrhyn Road, Kingston upon Thames, Surrey KTI 2EE, UK

Tel +442085472803

Email j.vanherwegen@kingston.ac.uk
Abstract: People with Williams syndrome (WS), a rare neurodevelopmental disorder that is caused by a deletion on the long arm of chromosome 7, often show an uneven cognitive profile with participants performing better on language and face recognition tasks, in contrast to visuospatial and number tasks. Recent studies have shown that this specific cognitive profile in WS is a result of atypical developmental processes that interact with and affect brain development from infancy onward. Using examples from language, face processing, number, and visuospatial studies, this review evaluates current evidence from eye-tracking and developmental studies and argues that domain general processes, such as the ability to plan or execute saccades, influence the development of these domain-specific outcomes. Although more research on eye movements in WS is required, the importance of eye movements for cognitive development suggests a possible intervention pathway to improve cognitive abilities in this population.

Keywords: Williams syndrome, eye movements, face processing, language, number, visuospatial abilities

\section{Introduction}

Williams syndrome (WS) is a rare neurodevelopmental disorder that results in a specific clinical, behavioral, and cognitive profile. This uneven cognitive profile has been of interest in order to unravel links between genetic makeup, brain, and behavioral outcomes. ${ }^{1-5}$ Studies have often claimed that WS provides evidence for a modular cognitive theory in which certain abilities can be spared or impaired and that these impairments can be directly linked to the WS genotype. ${ }^{6,7}$ Yet, as argued elsewhere, modules observed in adults emerge as a result of development, and domain-specific behavioral outcomes are supported by domain general cognitive processes from infancy onward. ${ }^{8,9}$ In order to study the connections between genes, brain, and behavioral outcomes, it is, therefore, important to understand how the cognitive processes in WS differ from those in typically developing (TD) populations and how they develop over time. ${ }^{8-11}$ In addition, a better understanding of what domain general abilities relate to performance in WS, including those that can explain areas of cognitive strength as well as a weakness, can further aid the development of ecologically valid training and intervention programs. Using evidence from two cognitive areas considered to be a strength (face and language processing) and two areas of weakness (visuospatial and number abilities), this review will evaluate how atypical looking behavior observed in eye-tracking as well as developmental studies in WS can explain some of the domainspecific outcomes in adulthood. Eye-tracking studies were identified through searches (through to January 2015) in PubMed, Web of Science, and Google Scholar using 
"Williams syndrome" and "eye tracking" as keywords (for a similar methodology, see Falck-Ytter ${ }^{12}$ applied to research on autism).

\section{WS: an uneven cognitive profile}

WS is a relatively rare neurodevelopmental disorder with a prevalence between one in 20,000 and one in 7,500 live births. ${ }^{13,14}$ It is caused by a microdeletion on the long arm of chromosome 7, affecting $\sim 26-28$ genes. ${ }^{15,16} \mathrm{WS}$ is diagnosed phenotypically based on clinical features as well as genetically using the gold standard fluorescent in situ hybridization testing to confirm the deletion of genes on chromosome 7.

WS is a multisystem disorder with a specific clinical, behavioral, and cognitive profile. ${ }^{17,18}$ During the last decade, WS has been of interest to researchers because of its uneven cognitive profile. Despite average overall IQ scores of 55, which indicates a mild-to-moderate intellectual disability, face processing and language abilities in WS are generally better compared to drawing, visuospatial, memory, and number processing. ${ }^{7,19,20}$ Because of the apparent discrepancy between the cognitive domains, especially between language abilities and spatial cognitive deficits, WS has been taken as evidence in favor of a modular theory in which specific, independent, and innate modules can be spared or impaired. ${ }^{7,19-21}$ However, this discrepancy between the strengths and weaknesses in WS only emerges over time with verbal abilities developing at a faster rate than nonverbal abilities. ${ }^{22}$ In addition, considerable heterogeneity has been reported when it comes to discrepancies within the WS profile with some participants scoring very low on language measures while others scoring within the normal range on visuospatial tasks. ${ }^{23,24}$ Finally, studies that have examined how abilities change throughout the life span have demonstrated that behavioral outcomes, even those in which WS are proficient, rely on different underlying cognitive processes, and thus, performance in WS is often atypical rather than just impaired (see Karmiloff-Smith et $\mathrm{al}^{25,26}$ and Laing et $\mathrm{al}^{27}$ for examples). For example, although participants with WS perform within the normal range on the Benton face recognition task, a task in which participants need to match unfamiliar faces, ${ }^{25,28,29}$ in-depth studies looking at the underlying cognitive processes of performance revealed that people with WS tend to look more at individual features of faces compared to controls who are more likely to process faces holistically. This suggests that individuals with WS might have weak central coherence and thus process faces atypically. ${ }^{25,30}$

Language is another area in which people with WS perform comparatively well, in that the speech of older individuals with
WS is better than one would expect for their overall cognitive abilities with good auditory memory and vocabulary skills, while syntactic, morphological, and pragmatic abilities are lower than predicted by chronological age. ${ }^{7,31}$ However, a review of language abilities in WS has shown little evidence of language abilities being better than nonverbal abilities. ${ }^{32}$ In addition, studies in infants with WS have found that not only the onset of language is delayed ${ }^{27,33}$ but also the performance on language tasks results from different underlying processes with language development following atypical pathways. ${ }^{27}$ For example, in contrast to TD infants, those with WS do not use referential pointing before they start using referential language. Yet, this lack of referential pointing could not be attributed to delayed motor skills in WS. ${ }^{27,34}$ In addition, children with WS showed a reduced ability to follow the experimenter's point. It has been argued that this impairment in pointing comprehension might affect their ability to learn vocabulary through parental pointing. ${ }^{35}$

Visuospatial cognition, often assessed by drawing tasks, block building, or pattern construction tasks, has been found to be an extreme weakness in WS as performance is much lower with respect to age norms and overall IQ (for a review, see Farran and Jarrold ${ }^{36}$ ) and develops at a much slower rate than in TD controls ${ }^{22}$ with performance scores on pattern construction tasks often at the floor level. ${ }^{37}$ There is evidence that even on visuospatial tasks where performance seems to be typical and in line with TD participants, participants with WS rely on atypical strategies. For example, visual illusions require participants to integrate a local part with surrounding elements into a coherent image. Behavioral studies have shown that participants with WS are susceptible to visual illusions to a similar extent as TD individuals. ${ }^{38,39}$ Yet, Grice et al ${ }^{40}$ demonstrated that this performance is supported by atypical neural behaviors. The Kanizsa square illusion occurs when four Pacman disks are correctly aligned so that the contours of a white square are perceived. This illusion is not perceived when the disks are rotated, and it has been argued that this illusion depends on low-level visual processes. Participants with WS were able to perceive the contours of the Kanizsa square illusion to a similar extent as TD age-matched controls, which suggests that low-level visual processes are intact in WS. However, the N1 component is a negative deflection in the event-related potential waveform at about $145-180 \mathrm{~ms}$ poststimulus that has been shown to be particularly sensitive and reliable measure of processing of contour illusions. Although the N1 response itself was typical in WS, differences in amplitude of the N1 to 
the different stimuli were abnormal compared to controls. This suggests that the ability to perceive illusions is supported by atypical cognitive processes in WS.

Finally, studies that have investigated number abilities in children and adults with WS have revealed that arithmetic skills are severely impaired even in adulthood. ${ }^{41,42}$ Although children with WS are proficient at counting sequences, ${ }^{43}$ they are impaired in their understanding of the meaning of counting or the cardinality principle. ${ }^{44}$ Research in TD populations has provided evidence that number abilities rely upon two different systems: one for precise and accurate number abilities, such as counting, which relates to language and memory abilities, and the second is nonverbal magnitude system that relies upon the ratios presented and relates to people's mental number line. ${ }^{45}$ It has been argued that this magnitude system is predictive of mathematical abilities later on in life, ${ }^{46,47}$ and this system has been found to be impaired in WS. ${ }^{43,48-50}$ However, mathematical abilities are not only impaired, there is also evidence that they develop atypically: whereas non-verbal spatial abilities predicted the variance in TD controls, performance on counting tasks in the WS group related to their verbal abilities. ${ }^{44}$ In addition, the developmental trajectory of the WS group was atypical as estimation abilities did not become faster and more accurate over time in contrast to TD children. ${ }^{48}$

\section{From domain general processes to domain specific outcomes}

Although recent studies have investigated how performance in WS changes over time, in order to really understand the strengths and weaknesses of the WS cognitive profile and how these develop over time, one needs to not only trace these developmental trajectories back to infancy but also evaluate how domain general processes influence domain specific outcomes. ${ }^{8,35}$

Visual exploration is important during a number of learning processes, especially early in life as it allows infants to explore their environment before their motor abilities have developed sufficiently to explore through grasp and touch. Visual exploration can occur without moving one's eyes or head (covert attention), but the greatest processing advantage happens by moving our eyes around (ie, through saccades) and fixating on places and objects within our environment (overt attention). Saccades do not happen at random but where and when the eye will move to is influenced by properties of the stimuli (bottom-up influences) as well as by the goals and interests of the viewer (top-down effects). ${ }^{51}$ In addition, eye movements are coupled to attention processes, in that a position is fixated upon (stimulus orienting), then processed (sustained attention), and then disengaged from (attention disengagement). According to the oculomotor readiness hypothesis, attention and eye movements are strongly related to each other as where the eyes focus is generally also where the attention is shifted to, and attention and eye movements are controlled by the same brain structures that are responsible for oculomotor control. ${ }^{52}$ Thus, in order to visually explore their environment, infants must learn to attend to objects and shift their attention to appropriate objects at the appropriate time. The ability to shift attention and make prompt saccades from a fixated target to a newer target under conditions of competition (ie, when both targets are present) develops from the age of 3-4 months onward in TD infants. ${ }^{53}$ Failing to make appropriate saccades, whether through attention or oculomotor difficulties, would result in infants not being able to scan their environments properly, which impacts on the development of higher cognitive abilities. Indeed, recent studies in autism spectrum disorders have found evidence that the atypical scanning of faces and social scenes later on in life can be linked to saccadic eye movement deficits in infancy, ${ }^{54}$ and thus, abnormal patterns of fixations can be used as a marker during early development of developmental disorders. ${ }^{55}$

Studies that have investigated eye movements in WS have shown that these are impaired from infancy onward. Using a double-step saccade paradigm, Brown et $\mathrm{al}^{56}$ found that while toddlers with WS have sustained attention similar to chronological and mental age-matched TD controls, they had problems orienting to a target as well as making a second saccade. Also, adult participants with WS demonstrated difficulties with eye movements for targets that appeared suddenly during a backward step saccade-adaptation task. ${ }^{5}$ In the backward step saccade task, participants were presented with a target dot on the left of the screen followed by a second dot on the right of the screen. However, during the test trials, the position of the second dot was moved slightly toward the middle of the screen while the participants were making a saccade toward it, therefore evoking a saccadic adaptation. Although 16 out of the 24 participants showed evidence of saccadic adaptation, all participants showed difficulties with moving their eyes accurately toward the second target. Best and Karmiloff-Smith, ${ }^{57}$ Karmiloff-Smith et al, ${ }^{58}$ and Van Herwegen and Karmiloff-Smith ${ }^{59}$ have argued that these differences in saccadic movements early on in life may affect how infants with WS learn from their environment and can be linked to cognitive outcomes later on in life. In addition, impaired abilities to plan or execute eye movements might 
explain the sticky fixation, an inability to disengage attention from a previously fixated target to a new target, that has been observed in WS. ${ }^{27,60}$ For example, in an eye-tracking study, it was found that toddlers with WS produced fewer voluntary eye movements in an antisaccade task, in which participants have to ignore a cue that appears on the opposite side of where the stimulus will appear, due to difficulties disengaging from the central stimulus. However, they did not show any difficulties in a Posner cueing paradigm and automatically paid attention to cued targets. In addition, they were slower to orient to invalidly cued targets. ${ }^{60}$ This shows that although toddlers with WS have issues with planning saccades, this is not caused by difficulties in orienting attention but rather by an inability to disengage from a previously fixed target. The following section will discuss how the inability to plan or execute eye movements, which results in sticky fixation, can partially explain cognitive performance, including both areas of strength and weakness in face processing, language learning, visuospatial abilities, and number development in WS.

People often report that individuals with WS show unusual eye contact, in that they often keep smiling and staring at people's faces during conversations. ${ }^{61}$ Indeed, eyetracking studies have shown that participants with WS look longer at faces in both static as well as complex dynamic social scenes in contrast to TD controls. ${ }^{62-67}$ In addition, participants with WS often focus longer on the eye region within the face. ${ }^{62,65}$ This fixation on faces has been argued to lead to an expertise for faces from an early age and is caused by hypersociability in WS. ${ }^{66}$ However, eye-tracking studies have shown that individuals with WS are not faster to detect a hidden face within unrelated landscape scenes. ${ }^{65}$ In addition, faces distract participants with WS no greater compared to controls in a visual search task and they display a similar face bias in a probe classification task. ${ }^{64}$ Participants with WS do, however, show longer fixations on the faces once they have been fixated upon compared to controls. ${ }^{63,65}$ Furthermore, a more recent study found that prolonged gazes to faces were only present when the social information was presented in the middle of the screen near a central fixation point but not when the stimuli were shown noncentrally. ${ }^{67}$ These studies demonstrate that the social bias in WS is likely to be caused by a difficulty to disengage from faces, which is caused by sticky fixation, rather than by hypersociability. There are currently no studies that have investigated scan paths while participants with WS were administered an upright/inversion task. Yet, a dysfunctional scanning ability whereby sticky fixation prevents backward and forward saccades between the different features of a face could explain the atypical local processing of features in WS. Indeed, research in TD and autism spectrum disorder populations have shown that eye gaze between facial features allows for a holistic processing of faces, which impacts on facial recognition. ${ }^{68,69}$

Research in TD children has revealed that joint attention, the ability to attend to an object or event vis-à-vis a communication partner, has an important role for early language development, in that it is thought to help children identify the intended referent of the parent's language and aid word-object mappings. ${ }^{70}$ Studies in infants with WS have shown that joint attention abilities are impaired, ${ }^{71}$ in that they are less likely to initiate joint attention than mentally matched controls. ${ }^{27}$ In addition, they were impaired in responding to joint attention, such as following where the examiner was pointing to, and this impairment predicted their language comprehension and production scores as measured by the MacArthur Communicative Development Inventories. ${ }^{27}$ Although this study did not directly record eye movements of the participants, it is possible that the failure to respond to pointing gestures is caused by an inability to disengage from the experimenter's face due to sticky fixation. Eye gaze plays an important role in the ability to respond to joint attention as shifts in eye gaze trigger a shift in orientation in order to align attention between individuals. $^{72}$ There are only two studies thus far that have evaluated gaze behavior in WS, but both have identified that gaze following is impaired in this population. ${ }^{73,74} \mathrm{~A}$ study by Tsirempolou et $\mathrm{al}^{74}$ tested eleven participants with WS and found that adults and adolescents are impaired in following eye gaze direction and rely longer on head orientation to identify where people are looking compared to TD children. A recent study examined eye movements while children and adults with WS aged 8-28 years old viewed pictures during a free-viewing condition as well as during a cued condition in which participants were asked to detect the target of an actor's gaze. ${ }^{73}$ Participants with WS followed gaze in a similar way to controls matched for nonverbal ability when explicitly cued for, but their atypical prolonged fixation on the faces prevented them from accurately identifying the correct target. Thus, the fact that participants with WS have difficulties in shifting their attention away from faces is likely to impair their gaze behavior, which impacts joint attention abilities with further cascading effects for their word-object mapping and early vocabulary acquisition abilities.

The studies discussed thus far have shown that participants with WS show longer fixations on faces due to sticky fixation. It can be argued that the failure to disengage from faces is caused by hypersociability rather than a problem 
with saccade movements per se (although see discussion above). However, participants with WS have also been found to show evidence of sticky fixation on tasks that do not involve any social aspects. For example, a study investigating the scanning patterns in a few infants with WS while they were looking at large numerical displays demonstrated that they only looked at a few dots and did not scan the entire display. ${ }^{58}$ This suggests that the inability to plan eye movements in WS causes them to only scan individual dots rather than the entire quantity, and this leads to failure to discriminate between large numerosities and impacts on the development of the magnitude system and number line as well as the development of their precise mathematical abilities. $^{58,59}$

As discussed above, individuals with WS show difficulties in visuospatial production tasks, such as drawing tasks and block construction tasks, and this could not be attributed to sensory vision problems. ${ }^{75}$ For example, when asked in the Navon task to copy large letters (eg, H) that are made up of small letters (eg, z), participants with WS are more likely to copy a few of the small letters that make up the large letter rather than the large letter itself. Earlier explanations that this impairment is caused by a local-processing bias have been refuted as no such bias has been reported in tasks where participants had to recognize rather than reproduce the stimuli. ${ }^{76}$ An alternative explanation could be that the inability to plan eye movements impairs the number of fixations people with WS make on a target as well as the gaze frequency (the switching between two targets), and this impairs task performance. Indeed, a recent study has illustrated that participants with WS looked less frequently at the model when copying a house compared to MA-matched controls. ${ }^{77}$ This has been argued to be caused by poor switching between the copy and the model as a result of poor eye movement planning. Looking less frequently to the model results in a higher working memory load, as one has to remember more elements when drawing, which causes atypical disoriented drawings. However, this study used button presses as a proxy for fixations on the model instead of traditional eye-tracking techniques. Thus, it is unclear where participants were looking during the task and whether they showed any evidence of sticky fixation. To date, only one study has investigated eye movements during a block design task using eye-tracking methodology. This study also demonstrated that children with WS fixated on models as well as their partial solutions less frequently than IQ-matched control children and TD adults. ${ }^{78}$ Again, this study failed to examine the average length of fixations and cannot provide any firm support for the suggestion that the infrequent fixations toward the model are caused by sticky fixation. In addition, Hoffman et $\mathrm{al}^{78}$ argue that the fact that participants with WS still made errors once they had fixated the model provides evidence that atypical looking alone cannot explain the errors made. Instead of being the cause for low accuracy, atypical looking might be the result of participants' prediction that they would fail the task anyway. As described below, task performance relies upon a number of cognitive, behavioral, and environmental factors, and thus, it is likely that poor eye movement planning alone cannot explain the performance on visuospatial block design tasks. Indeed, it cannot explain why difficulties with eye movement planning can produce difficulties in production but not perception tasks. Nevertheless, sticky fixation may also provide an explanation for the atypical neural performance observed during visual illusions. Studies in TD participants have illustrated that the $\mathrm{N} 1$ component is sensitive to illusory contours in event-related potential studies and that an increase in N1 amplitude relates to a global search relative to a local search. ${ }^{79}$ In addition, TD participants often make a number of successive fixations at various spatial locations to enhance the visual illusion, and thus, it is important to combine the information from these different saccades. ${ }^{80}$ As mentioned before, Grice et al have shown that, although participants with WS can perceive visual illusions similar to TD controls, the neural mechanisms that support this ability are atypical. ${ }^{40}$ Currently, no eye-tracking studies have examined eye movements during illusion perception tasks in WS. However, it is possible that the fact that no differentiation was found in N1 amplitude between the different stimuli in WS, in contrast to controls, might suggest that participants with WS fail to use a global strategy, probably caused by the fact that they only make a single fixation. ${ }^{40}$ If this is the case, it would show that although behavioral outcomes for perceptual tasks are similar to controls, the low-level visual processes that support higher level processing are impaired in WS.

\section{Current limitations and future studies}

Although deficient eye movement planning resulting in sticky fixation can explain a number of strengths and difficulties observed in the WS cognitive profile, research remains limited, in that the studies often included small sample sizes and there is a lack of longitudinal as well as developmental studies. Studies investigating eye movements from infancy onward across development are necessary, in that even when we know that the scanning patterns in WS infants are atypical for a certain type of stimuli, different developmental 
outcomes are possible. For example, individuals with WS might develop compensatory strategies. Alternatively, their scanning abilities might be merely delayed or remain atypical throughout development. Thus far, studies have shown that scanning paths remain atypical in WS for social stimuli, ${ }^{63-65}$ yet research, including eye tracking with nonsocial stimuli, is still limited. In addition, most of the existent studies have included only a small number of participants, often from a wide age range, which might explain the large variability in the data and also why some studies did not find any evidence of atypical scanning or difficulties to disengage when using social stimuli in WS. ${ }^{81-83}$ Comparing eye movements on social and nonsocial stimuli will further our understanding of how hypersociability and attention difficulties in general contribute to atypical scanning patterns.

In addition, there are methodological issues that make comparisons between studies difficult, including the different kinds and methods of eye tracking as well as different analyses (see Hanley ${ }^{84}$ for a discussion). For example, while some studies tracked participants' eyes at $250 \mathrm{~Hz}$, others have used much lower frequencies (eg, $60 \mathrm{~Hz}$ or $120 \mathrm{~Hz}$ ), therefore relying on fewer samples of where the eyes were positioned within a certain time frame. Also the type of stimuli, for example whether static versus dynamic scenes were used, has been found to affect scanning paths in WS. ${ }^{64}$

It is also possible that abilities that seem to be unrelated in adulthood are related in infancy and can explain some aspects of the WS cognitive profile. For example, research has shown that infants with WS focus on auditory input. ${ }^{34}$ Thus, upon hearing their mother's voice, infants will turn to her upon which they will see their mother's face. It is therefore possible that the fascination with faces in WS stems from a focus on auditory stimuli combined with problems with visual disengagement and a heightened social drive. Although it is possible that such domain specific abilities explain to an extent the face-processing and language abilities, there is limited evidence that hypersociability alone can explain the atypical behavior observed on nonverbal tasks. Recent studies have shown that the atypical scanning paths for social stimuli in WS are related to their anxiety and social reciprocity. ${ }^{82}$ Thus, future studies should not only focus on eye movements but also on a number of domain general factors as well as environmental factors. For example, numerical abilities depend on verbal abilities, visuospatial abilities, attention, working memory, anxiety levels, and environmental influences. Therefore, any deficit in one or more of these domains from infancy onward can affect numerical abilities later on in life.
Finally, with exception of motion perception, ${ }^{85,86}$ very few studies have investigated the oculomotor system in WS directly, and it is unclear how stimulus-driven factors such as color, ${ }^{87}$ luminance, and visual clutter influence fixation duration in WS. However, it has been shown that adults with WS have a less efficient oculomotor system that results in large saccadic variability. ${ }^{5,88}$ Yet, saccades did improve during a saccade-adaptation task, which suggests that individuals with WS would benefit from training programs aimed to improve saccadic control. Such training studies should be aimed at young participants with WS as a recent review has shown that, although there are not many training paradigms that improve attentional control with positive transfer to other cognitive abilities, training studies aimed at younger participants reported more widespread transfer of training effects. ${ }^{89}$

\section{Conclusion}

Individuals with WS often show an uneven cognitive profile in which language and face-processing abilities are better in comparison to number and visuospatial abilities. However, developmental studies have shown that this uneven cognitive profile is the outcome of a number of atypical developmental processes. Specifically, atypical domain general processes, such as sticky fixation, which result from problems with saccade planning, influence and interact with specific cognitive developmental processes from infancy onward. There is probably a very complex relationship between attention and the cognitive processes described above, and it is certain that other domain general factors such as executive functioning, auditory processing, and low-level visual abilities play a role in the language, face processing, number, and visuospatial development in WS. Yet, the current overview has shown that differences in one such domain general ability, ie, scanpaths in infancy, can explain a number of behavioral outcomes observed in adults with WS. This is very promising for training studies, in that it was found that although participants with WS have problems with saccade planning, they demonstrated saccadic adaptation, which shows that they do have the capacity for saccadic motor learning and that their oculomotor system can be trained. ${ }^{5}$

Nonetheless, the number of eye-tracking studies providing concrete evidence about eye movements in WS is still limited and there is a lack of developmental studies examining the role of eye movements in cognitive processes from infancy onward. Such research is needed in order to fully appreciate the importance of saccadic movements in relation to the uneven cognitive profile in WS, especially as not 
all studies have found evidence for sticky fixation in WS. Therefore, large studies are required that allow the investigation of subtypes and examine the individual differences within the WS cognitive profile and how these relate to their fixation patterns.

\section{Acknowledgments}

I would like to thank Gaia Scerif and the reviewers for comments on an earlier draft of this manuscript.

\section{Disclosure}

The author reports no conflicts of interest in this work.

\section{References}

1. Eckert MA, Galaburda AM, Mills DK, Bellugi U, Korenberg JR, Reiss AL. The neurobiology of Williams syndrome: cascading influences of visual system impairment? Cell Mol Life Sci. 2006;63: $1867-1875$.

2. Korenberg JR, Chen XN, Hirota H, et al. Genome structure and cognitive map of Williams syndrome. J Cogn Neurosci. 2000;12(1):89-107.

3. Meyer-Lindenbrug A, Mervis CB, Faith K. Neural mechanisms in Williams syndrome: a unique window to genetic influences on cognition and behaviour. Nat Rev Neurosci. 2006;7:380-393.

4. Reiss AL, Eckert MA, Rose FE, et al. An experiment of nature: brain anatomy parallels cognition and behaviour in Williams syndrome. J Neurosci. 2004;24(2):5009-5015.

5. Van der Geest JN, Lagers-van Haselen GC, Frens MA. Saccadic adaptation in Williams-Beuren syndrome. Invest Ophthalmol Vis Sci. 2006; 47(4):1464-1468.

6. Bellugi U, Adolphs R, Cassandry C, Chiles M. Towards the neural basis for hypersociability in a genetic syndrome. Neuroreport. 1999; 10:1-5

7. Bellugi U, Lichtenberger L, Jones W, Lai Z, St-George M. The neurocognitive profile of Williams syndrome: a complex pattern of strengths and weaknesses. J Cogn Neurosci. 2000;12(Suppl 1):7-29.

8. Karmiloff-Smith A. Development itself is the key to understanding developmental disorders. Trends Cogn Sci. 1998;2:389-398.

9. Karmiloff-Smith A. Modules, genes and evolution: what have we learned from atypical development? In: Munakata Y, Johnson M, editors. Processes of Change in Brain and Cognitive Development. Oxford: Oxford University Press; 2006:563-583.

10. Karmiloff-Smith A. Nativism versus neuroconstructivism: rethinking the study of developmental disorders. Dev Psychol. 2009;45(1):56-63.

11. Thomas MSC, Karmiloff-Smith A. Are developmental disorders like cases of adult brain damage? Implications from connectionist modeling. Behav Brain Sci. 2002;25:727-788.

12. Falck-Ytter Y, Bölte S, Gredebäck G. Eye tracking in early autism research. J Neruodev Disord. 2013;5(1):28.

13. Morris CA, Demsey SA, Leonard CO, Dilts C, Blackburn BL. Natural history of Williams syndrome: physical characteristics. J Pediatr. 1988; 113(2):318-326.

14. Strömme P, Bjornstad PG, Ramstad K. Prevalence estimation of Williams syndrome. J Child Neurol. 2002;17:269-271.

15. Tassabehji M. Williams-Beuren syndrome: a challenge for genotypephenotype correlations. Hum Mol Genet. 2003;12(2):229-237.

16. Donnai D, Karmiloff-Smith A. Williams syndrome: from genotype through to the cognitive phenotype. Am J Med Genet. 2000;97: 164-171.

17. Martens MA, Wilson SJ, Reutens DC. Research review: Williams syndrome: a critical review of the cognitive, behavioural, and neuroanatomical phenotype. J Child Psychol Psychiatry. 2008;49:576-608.
18. Carrasco X, Castillo S, Aravena T, Rothhammer P, Aboitiz F. Williams syndrome: pediatric, neurologic, and cognitive development. Pediatr Neurol. 2005;32(3):166-172.

19. Bellugi U, Wang PP, Jernigan TL. Williams syndrome: an unusual neuropsychological profile. In: Broman SH, Graham J, editors. Atypical Cognitive Deficits in Developmental Disorders: Implications for Brain Function. Hillsdale, NJ: Lawrence Erlbaum Associates; 1994:23-56.

20. Mervis CB, Robinson BF, Bertrand J, Morris CA, Klein-Tasman BP, Armstrong SC. The Williams syndrome cognitive profile. Brain Cogn. 2000;44:604-628.

21. Bellugi U. Dissociation between language and cognitive functions in Williams syndrome. In: Bishop DMV, Mogford K, editors. Language Development in Exceptional Circumstances. Edinburgh: Churchill Livingstone; 1988:177-189.

22. Jarrold C, Baddeley AD, Hewes AK, Phillips C. A longitudinal assessment of diverging verbal and non-verbal abilities in the Williams syndrome phenotype. Cortex. 2001;37(3):423-431.

23. Porter MA, Colthaert M. Cognitive heterogeneity in Williams syndrome. Dev Neuropsychol. 2005;27(2):275-306.

24. Stojanovik V, Perkins M, Howard S. Linguistic heterogeneity in Williams syndrome. Clin Linguist Phon. 2006;20(7\&8):547-552.

25. Karmiloff-Smith A, Thomas M, Annaz D, et al. Exploring the Williams syndrome face-processing debate: the importance of building developmental trajectories. J Child Psychol Psychiatry. 2004;45(7): $1258-1274$

26. Karmiloff-Smith A, Grant J, Berthoud I, Davies M, Howlin P, Udwin O. Language and Williams syndrome: how intact is "intact"? Child Dev. 1997;68(2):246-262.

27. Laing E, Butterworth G, Ansari D, et al. Atypical development of language and social communication in toddlers with Williams syndrome. Dev Sci. 2002;5(2):233-246.

28. Plesa-Skwerer D, Faja S, Schofield C, Verbalis A, Tager-Flusberg H. Perceiving facial and vocal expressions of emotion in individuals with Williams syndrome. Am J Ment Retard. 2006;111(1):15-26.

29. Tager-Flusberg H, Plesa-Skwerer D, Faja S, Joseph RM. People with Williams syndrome process faces holistically. Cognition. 2003;89: $11-24$.

30. Deruelle C, Mancini J, Livet MO, Cassé-Perrot C, de Schonen S. Configural and local processing of faces in children with Williams syndrome. Brain Cogn. 1999;41:276-298.

31. Laws G, Bishop DVM. Pragmatic language impairment and social deficits in Williams syndrome: a comparison with Down's syndrome and specific language impairment. Int J Lang Commun Disord. 2004;39(1): 45-64.

32. Brock J. Language abilities in Williams syndrome: a critical review. Dev Psychopathol. 2007;19:97-127.

33. Mervis CB, Robinson BF, Rowe ML, Becerra AM, Klein-Tasman BP. Language abilities in Individuals with Williams syndrome. In: Abbeduto L, editor. International Review of Research in Mental Retardation. Orlando, FL: Academic Press; 2003:35-81.

34. Mervis CB, Morris CA, Bertrand J, Robinson BF. Williams syndrome: findings from an integrated program of research. In: Tager-Flusberg $\mathrm{H}$, editor. Neurodevelopmental Disorders. Cambridge: MIT Press; 1999:65-110.

35. Karmiloff-Smith A. Atypical epigenesis. Dev Sci. 2007;10(1):84-88.

36. Farran EK, Jarrold C. Visuo-spatial cognition in Williams syndrome: reviewing and accounting for the strengths and weaknesses in performance. Dev Neuropsychol. 2003;23(1-2):173-200.

37. Van Herwegen J, Rundblad G, Davelaar EJ, Annaz D. Variability and standardised test profiles in typically developing children and children with Williams syndrome. Br J Dev Psychol. 2011;29:883-894.

38. Farran EK, Cole VL. Perceptual grouping and distance estimates in typical and atypical development: Comparing performance across perception, drawing and construction tasks. Brain Cogn. 2008;68:157-165.

39. Palomares M, Ogbonna C, Landau B, Egeth H. Normal susceptibility to visual illusions in abnormal development: evidence from Williams syndrome. Perception. 2009;38:186-199. 
40. Grice SJ, Haan MD, Halit H, et al. ERP abnormalities of illusory contour perception in Williams syndrome. Neuroreport. 2003;14:1773-1777.

41. Udwin O, Davies M, Howlin P. A longitudinal study of cognitive and education attainment in Williams syndrome. Dev Med Child Neurol. 1996;38:1020-1029.

42. O’Hearn K, Landau B. Mathematical skill in individuals with Williams syndrome: evidence from a standardized mathematics battery. Brain Cogn. 2007;64:238-246.

43. Paterson SJ, Girelli L, Butterworth B, Karmiloff-Smith A. Are numerical impairments syndrome specific? Evidence from Williams syndrome and Down's syndrome. J Child Psychol Psychiatry. 2006;47(2):190-204.

44. Ansari D, Donlan C, Thomas M, Ewing S, Karmiloff-Smith A. What makes counting count? Verbal and visuo-spatial contributions to typical and atypical number development. J Exp Child Psychol. 2003;85: 50-62.

45. Feigenson L, Dehaene S, Spelke ES. Core systems of number. Trends Cogn Sci. 2004;8(7):307-314.

46. Bonny JW, Lourenco SF. The approximate number system and its relation to early math achievement: evidence from the preschool years. J Exp Child Psychol. 2012;114:375-388.

47. Mazzocco MMM, Feigenson L, Halberda J. Preschoolers' precision of the approximate number system predicts later school mathematics performance. PLOS ONE. 2011;6(9):e23749.

48. Ansari D, Donlan C, Karmiloff-Smith A. Typical and atypical development of visual estimation abilities. Cortex. 2007;43:758-768.

49. Krajcsi A, Lukacs A, Igacs J, Racsmany M, Pleh C. Numerical abilities in Williams syndrome: dissociating the analogue magnitude system and verbal retrieval. J Clin Exp Neurospychol. 2009;31(4):439-446.

50. Van Herwegen J, Ansari D, Xu F, Karmiloff-Smith A. Small and large number processing in infants and toddlers with Williams syndrome. Dev Sci. 2008;11(5):637-643.

51. Rayner K. Eye movements in reading and information processing: 20 years of research. Psychol Bull. 1998;124:372-422.

52. Hoffman J, Subramaniam B. The role of visual attention in saccadic eye movements. Percept Psychophys. 1995;57:787-795.

53. Atkinson J, Hood B, Wattam-Bell J, Braddick OJ. Changes in infants' ability to switch visual attention in the first three months of life. Perception. 1992;21:643-653.

54. Neumann D, Spezio ML, Piven J, Adoplhs R. Looking you in the mouth: abnormal gaze in autism resulting from impaired top-down modulation of visual attention. Soc Cogn Affect Neurosci. 2006;1(3):194-202.

55. Wass S, Jones EJH, Gigla T, et al. Shorter spontaneous fixation durations in infants with later emerging autism. Nature. 2015;5:8284.

56. Brown JH, Johnson MH, Paterson SJ, Gilmore R, Longhi E, KarmiloffSmith A. Spatial representation and attention in toddlers with Williams syndrome and Down syndrome. Neuropsychologia. 2003;41: 1037-1046.

57. Best G, Karmiloff-Smith A. Why development matters in neurodevelopmental disorders. In: Van Herwegen J, Riby D, editors. Neurodevelopmental Disorders: Research Challenges and Solutions. Hove: Psychology Press; 2014:19-33.

58. Karmiloff-Smith A, D'Souza D, Dekker T, et al. Genetic and environmental vulnerabilities: the importance of cross-syndrome comparisons. Proc Natl Acad Sci U S A. 2012;109(2):17261-17265.

59. Van Herwegen J, Karmiloff-Smith A. Genetic developmental disorders and numerical competence across the lifespan. In: Cohen Kadosh R, Dowker A, editors. Oxford Handbook of Numerical Cognition. Oxford: Oxford University Press; In press 2015.

60. Cornish K, Scerif G, Karmiloff-Smith A. Tracing syndrome-specific trajectories of attention across the life-span. Cortex. 2007;43:672-685.

61. Jones W, Bellugi U, Chiles M, Reilly J, Lincoln A, Adoplhs R. Hypersociability in Williams syndrome. J Cogn Neurosci. 2000;12(Suppl 1): 30-46.

62. Riby DM, Hancock PJB. Viewing it differently: social scene perception in Williams syndrome and autism. Neuropsychologia. 2008;46: $2855-2860$
63. Riby DM, Hancock PJB. Looking at movies and cartoons: eye-tracking evidence from Williams syndrome and autism. J Intellect Disabil Res. 2009;53(2):169-218.

64. Riby DM, Jones N, Brown PH, et al. Attention to faces in Williams syndrome. J Autism Dev Disord. 2011;41(9):1228-1239.

65. Riby DM, Hancock PJB. Do faces capture the attention of individuals with Williams syndrome or autism? Evidence from tracking eye movements. J Autism Dev Disord. 2009;39(3):421-431.

66. Porter MA, Shaw T, Marsh PJ. An unusual attraction to the eyes in Williams-Beuren syndrome: a manipulation of facial affect while measuring face scanpaths. Cogn Neuropsychiatry. 2010;15(6):505-530.

67. Williams TA, Porter MA, Langdon R. Viewing social scenes: a visual scan-path study comparing fragile $\mathrm{X}$ syndrome and Williams syndrome. J Autism Dev Disord. 2013;43:1880-1894.

68. Henderson JM, Williams CC, Falk RK. Eye movements are functional during face learning. Mem Cognit. 2005;33(1):98-106.

69. Wilson CE, Palermo R, Brock J. Visual scan paths and recognition of facial identity in autism spectrum disorder and typical development. PLoS One. 2012;7(5):e37681

70. Morales M, Mundy P, Delgado CEF, et al. Responding to joint attention across the 6- to 24-month age period and early language acquisition. J Appl Dev Psychol. 2000;21:283-298.

71. Bertrand J, Mervis C, Rice CE, Adamson, L. Development of joint attention by a toddler with Williams syndrome. Paper presented at: the Gatlinberg Conference on Research and Theory in Mental Retardation and Developmental Disabilities, Gatlinberg; 1993.

72. Langton SRH, Bruce V. Reflexive visual orienting in response to the social attention of others. Vis Cogn. 1999;6:541-567.

73. Riby DM, Hancock PJB, Jones N, Hanley M. Spontaneous and cued gaze-following in autism and Williams syndrome. J Neurodev Disord. 2013;5(1):13.

74. Tsirempolou E, Lawrence K, Lee K, Ewing S, Karmiloff-Smith A. Understanding the social meaning of the eyes: is Williams syndrome so different from autism? World J Pediatr. 2006;2(4):288-296.

75. Atkinson J, Anker S, Braddick O, Nokes L, Mason A. Visual and visuospatial development in young children with Williams syndrome. Dev Med Child Neurol. 2001;43:330-337.

76. Farran EK, Jarrold C, Gathercole SE. Divided attention, selective attention and drawing: processing preferences in Williams syndrome are dependent on the tasks administered. Neuropsychologia. 2003;41: 676-687.

77. Hudson KD, Farran EK. Looking around houses: attention to a model when drawing complex shapes in Williams syndrome and typical development. Res Dev Disabil. 2013;34:3029-3039.

78. Hoffman JE, Landau B, Pagani B. Spatial breakdown in spatial construction: evidence from eye fixations in children with Williams syndrome. Cogn Psychol. 2003;46:260-301.

79. Consci M, Tollner T, Leszczynski M, Muller HJ. The time-course of global and local attentional guidance in Kanizsa-figure detection. Neuropsychologia. 2011;49:2456-2464.

80. Liinasuo M, Rovamo J, Kojo I. Effects of spatial configuration and number of fixations on Kanizsa triangle detection. Invest Ophthalmol Vis Sci. 1997;38:2554-2565.

81. Hanley M, Riby DM, Caswell S, Rooney S, Back E. Looking and thinking: how individuals with Williams syndrome make judgments about mental states. Res Dev Disabil. 2013;34:4466-4476.

82. Kirk H, Hocking D, Riby DM, Cornish K. Linking social behaviour and anxiety to attention to emotional faces in Williams syndrome. Res Dev Disabil. 2013;34:4608-4616

83. Doherty-Sneddon G, Whittle L, Riby DM. Gaze aversion during social style interactions in autism spectrum disorders and Williams syndrome. Res Dev Disabil. 2013;34(1):616-626.

84. Hanley M. Eye-tracking and neurodevelopmental disorders: evidence from cross-syndrome comparisons. In: Van Herwegen J, Riby D, editors. Neurodevelopmental Disorders: Research Challenges and Solutions. Hove: Psychology Press; 2014:219-240. 
85. Atkinson A, Braddick O. From genes to brain development to phenotypic behavior: "dorsal-stream vulnerability" in relation to spatial cognition, attention, and planning of actions in Williams syndrome (WS) and other developmental disorders. Prog Brain Res. 2011;189:261-263.

86. Castelo-Branco M, Mendes M, Sebastião AR, et al. Visual phenotype in Williams-Beuren syndrome challenges magnocellular theories explaining human neurodevelopmental visual cortical disorders. J Clin Invest. 2007;117(12):3720-3729.
87. Farran EK, Cranwell MB, Alvarez J, Franklin A. Colour discrimination and categorization in Williams syndrome. Res Dev Disabil. 2013;34(10): 3352-3360.

88. van der Geest JN, Lagers-van Haselen GC, van Hagen JM, et al. Saccade dysmestria in Williams-Beuren syndrome. Neuropsychologia. 2004;42(5):569-576.

89. Wass SV, Scerif G, Johnson MH. Training attentional control and working memory - is younger-better? Dev Rev. 2012;32:360-387.

\section{Publish your work in this journal}

Psychology Research and Behavior Management is an international, peerreviewed, open access journal focusing on the science of psychology and its application in behavior management to develop improved outcomes in the clinical, educational, sports and business arenas. Specific topics covered include: Neuroscience, memory \& decision making; Behavior modification \& management; Clinical applications; Business \& sports performance management; Social and developmental studies; Animal studies. The manuscript management system is completely online and includes a quick and fair peer-review system. Visit http://www.dovepress. com/testimonials.php to read real quotes from published authors.

Submit your manuscript here: http://www.dovepress.com/psychology-research-and-behavior-management-journal 